\title{
Iron Supplementation is Underutilized after Hospitalization for Gastrointestinal Bleeding
}

\author{
Marina Baskharoun', Sara Goff ${ }^{1}$, Michael Bromberg², Yiting Li ${ }^{3}$, Lan Xu ${ }^{4}$, Frank Friedenberg ${ }^{5^{*}}$ \\ ${ }^{1}$ Department of Internal Medicine, Lewis Katz School of Medicine at Temple University, Philadelphia, (PA,) USA \\ ${ }^{2}$ Section of Hematology Lewis Katz School of Medicine at Temple University, Philadelphia, (PA,) USA \\ ${ }^{3}$ Department of Internal Medicine, Seton Hall University School of Health and Medical Sciences, Saint Francis \\ Medical Center, Trenton, (NJ,) USA \\ ${ }^{4}$ College of Public Health, University of South Florida, Tampa, (FL, ) USA \\ ${ }^{5}$ Gastroenterology Section, Lewis Katz School of Medicine at Temple University, Philadelphia, (PA,) USA
}

\begin{abstract}
Introduction: Iron deficiency anemia (IDA) is common in the hospital setting and is frequently caused by gastrointestinal bleeding (GIB). While treatment is aimed at the underlying cause of IDA, it is also targeted at replenishing iron stores to reduce anemia progression and decrease the risk of end organ damage.

Objective: The primary aim of this study was to assess whether patients hospitalized with IDA secondary to GIB received iron supplementation upon discharge.

Methods: Retrospective analysis evaluating 992 patients admitted to our tertiary care hospital from 1/1/17 $12 / 1 / 17$ who underwent endoscopy for GIB. IDA was defined as ferritin $\leq 30$, iron saturation $\leq 10 \%$ or a $\geq 2$ gram drop from the patient's baseline hemoglobin. A secondary endpoint assessed readmission rates within a 180-day follow up period after discharge and associated morbidity and mortality.

Results: A total of 228 patients met inclusion criteria for analysis. There were 115 males (50.4\%) with an overall mean age of $62.6 \pm 2.1 \mathrm{y}$. Overall, $106(46.5 \%)$ patients eligible by our criteria to receive iron therapy were discharged on this therapy. In regression analysis, receiving iron $(\mathrm{OR}=13.6 ; 95 \% \mathrm{CI}, 7.0-26.6)$ or a blood transfusion $(2.72 ; 1.1-6.9)$ during hospitalization were independently associated with discharge on iron. Discharge on iron was not associated with readmission but there was a non-significant trend toward anemia improvement for those supplemented with iron.

Conclusions: At our institution, physicians failed to provide iron supplementation on discharge to over $50 \%$ of eligible patients. Patients diagnosed with IDA secondary to GIB are more likely to be discharged with iron supplementation if it was started during hospitalization or they received a blood transfusion. We believe the medication reconciliation performed automatically by the electronic medical record (EMR) at the time of discharge had a significant impact on this finding.
\end{abstract}

Keywords: Gastrointestinal Bleeding, Iron deficiency anemia,

\section{Introduction}

Iron deficiency anemia (IDA) is a commonly encountered disorder that can have significant morbidity and mortality. Iron is critical in multiple molecular pathways including cellular respiration and DNA synthesis. IDA affects a large proportion of the world's population with a global prevalence of $32.9 \%$ in 2010 and is the leading cause of anemia [1].
Corresponding Author: Frank Friedenberg, Chief, Gastroenterology, Professor, Medicine Lewis Katz School of Medicine at Temple University 3401 North Broad Street Philadelphia, PA 19107. Received date: August 12, 2020; Accepted date: August 25, 2020; Published date: August 26, 2020.

DOI: https://doi.org/10.31546/2732-5652.1002 
Recent U.S. data shows that an average of $5.6 \%$ of the population has anemia with $1.5 \%$ reaching moderate-severe anemia [2]. The major causes of IDA are decreased intake, reduced absorption, and blood loss. In resource-rich countries such as the United States, the major cause of IDA is through blood loss and insufficient dietary intake [3].

Iron is stored primarily in the liver parenchyma and the reticuloendothelial cells of the bone marrow, liver, and spleen. Methods for assessing iron storage include the serum ferritin, total iron-binding capacity (TIBC), and examining bone marrow specimens. Serum iron represents the amount of iron that is bound to transferrin, the iron transporting protein in the blood. Serum iron is available to be incorporated into hemoglobin (hgb) for the development of erythroblasts. The daily turnover of iron is about $20 \mathrm{mg}$ and humans are only able to absorb about 1-2 mg daily. Therefore the majority of daily iron available to meet requirement is consequently recycled iron from senescent red blood cells.

Together, the serum iron level and TIBC can be used to calculate the transferrin saturation, which if less than $15 \%$ is suggestive of IDA [4]. The serum ferritin level represents the body's iron stores but can be elevated in states of inflammation, malignancy and liver disease. However, in the absence of inflammation the combination of low transferrin saturation and a ferritin level of less than $25 \mathrm{ng} / \mathrm{ml}$ confirms IDA [5]. It has been observed in phlebotomy studies that both a fall in transferrin saturation to less than $16 \%$ and a decrease in serum ferritin below $12 \mu \mathrm{g} 1^{-1}$ occur at approximately the same time, suggesting that either marker can be used as evidence of iron deficiency [6]. Aside from absolute iron deficiency, some individuals may display functional iron deficiency. Functional iron deficiency refers to individuals who have adequate iron stores but are not able to utilize the iron for erythropoiesis. Functional iron deficiency is identified by the transferrin saturation, serum transferrin receptor, and the presence and degree of anemia and can be seen in patients with chronic inflammatory states such as end-stage renal disease (ESRD).

One of the most common causes of IDA is blood loss due to gastrointestinal (GI) bleeding. Most patients who present with an acute GI bleed experience significant iron losses. The purpose of our study was to determine whether patients admitted with GI bleeding resulting in significant anemia were properly discharged with iron supplementation, either a prescription for oral iron or arrangements for parenteral infusions. We aimed to explore factors independently associated with receiving this therapy. We also aimed to explore the hypothesis that patients not appropriately discharged on iron would experience higher cardiovascular morbidity and hospital re-admission rates.

\section{Patients and Methods}

We performed a retrospective review of all patients hospitalized with GI bleeding who underwent endoscopy between January 1, 2017 and December 31, 2017. Criteria were established a priori as to eligibility for supplemental iron at the time of discharge. Patients had to have $>1$ of the following: ferritin $\leq 30 \mathrm{ng} / \mathrm{ml}$; iron saturation $\leq 10 \% ; \geq 2 \mathrm{~g} / \mathrm{dl}$ drop from the patient's baseline hgb concentration along with a discharge value of $<10.0 \mathrm{~g} / \mathrm{dL}$ due to GI bleeding. We chose an iron saturation threshold of $<10 \%$ as, at this value, most clinicians would agree that this is consistent with IDA requiring supplementation. $\mathrm{Hgb}<10$ was used as a cut-off to determine whether patients should be discharged with iron as this threshold has been associated with a higher risk of re-bleeding and mortality [7]. The iron studies had to be within one year prior to admission for GI bleeding not necessarily diagnosed during the admission for GI bleeding. We excluded patients with active malignancy, prior abdominal surgery, underlying malabsorptive or hematologic disorders, hgb $\geq 10$ on discharge, or those who died during hospitalization. We recorded the hgb on admission, nadir, and discharge and whether blood transfusion(s) and/or iron supplementation (oral or parenteral) were given prior to discharge. In addition, the use of anticoagulants and antiplatelet agents prior to admission was recorded along with alcohol and NSAID use. A post-discharge period of 180 days was reviewed to assess outpatient hgb levels and whether hospital readmission occurred. Follow-up was terminated at $<180$ days if the patient was readmitted, died, or was lost to follow-up during that period.

\section{Statistical Analysis}

Continuous variables were evaluated for normality using histograms. For normally distributed continuous data, comparisons between independent groups were made using Student's t-tests. Non-parametric analyses were performed using the Mann-Whitney $U$ test. Categorical variables were compared between groups for significance using the $\chi^{2}$ test. From these univariate analyses all comparisons between variables that yielded a 2 -tailed $\mathrm{P}$ value $<0.05$ were preserved for regression analysis. We then performed binary logistic regression analysis using the variable "received iron on discharge" as the dependent variable 
and imputed independent variables from the univariate analysis. For the regression model, hgb values were cut at 7.0 $\mathrm{g} / \mathrm{dL}$ because this is the threshold when action is recommended to increase the hgb either through blood transfusion or iron supplementation [6]. The results from the regression analysis were expressed as adjusted odds ratio with associated 95\% confidence interval. All analyses were performed using SPSS v 25.0 (IBM Corporation).

\section{Results}

From 992 records we identified 228 patients who met inclusion criteria (Figure 1). There were 115 males $(50.4 \%)$ with an overall mean age of $62.6 \pm 2.1 \mathrm{y}$. The major etiologies of identified bleeding included peptic ulcer disease $(n=25)$, GI angioectasia $(n=18)$, esophageal varices $(n=14)$, duodenal ulcer $(n=14)$, and diverticular disease $(n=11)$. A source of bleeding was not identified in $97(42.5 \%)$ patients who met inclusion criteria. Overall, 106 (46.5\%) patients eligible by our criteria to receive iron therapy were discharged on this therapy. Therefore, $122(53.5 \%)$ patients with confirmed iron deficiency, or $\mathrm{a} \geq 2 \mathrm{~g} / \mathrm{dl}$ drop from the patient's baseline hgb with a final value of $<10.0$ due to GI bleeding, were not prescribed iron on discharge. Admission hgb (Figure 2) was significantly lower (7.6 vs. 9.1, p<0.001) as was nadir hgb (6.4 vs. $6.8, \mathrm{p}=0.02$ ) for those sent home on iron however there was no significant difference in the discharge hgb (Table 1).
There were $82(36 \%)$ patients with a nadir hgb $<7.0$ $\mathrm{g} / \mathrm{dL}$. Iron indices were significantly lower for those discharged on iron however both groups, on average, met criteria for IDA. Those discharged on iron were more likely to receive a blood transfusion $(85.8$ vs. $71.3 \%, \mathrm{p}=0.008)$ and/or supplemental iron (70.8 vs. $15.6 \%, \mathrm{p}<0.001)$ during hospitalization.

Prior to regression modeling, the variables "ferritin" and "transferrin saturation" were removed as only 71 $(31.1 \%)$ patients had these values determined. The patient's admission and nadir hgb values (using a cut point of $<7 \mathrm{~g} / \mathrm{dL}$ ) were not independently associated with whether they received iron upon discharge; OR = 1.9 ; 95\% CI, 0.99-3.7 and $1.1 ; 0.8-1.5$ respectively (Table 1). However, receiving iron $(\mathrm{OR}=13.6$; $95 \%$ CI, 7.0-26.6) or a blood transfusion (2.72; 1.1-6.9) during hospitalization were independently associated with discharge on iron.

We reviewed events post-discharge for each patient for up to 180 days. Ultimately our mean length of followup was $84 \pm 64$ days due to death, readmission, and loss to follow-up. As shown in Table 2, discharge on iron was not associated with readmission but there was a non-significant trend toward anemia improvement for those supplemented with iron.

Table 1: Demographic Characteristics.

\begin{tabular}{|c|c|c|c|c|}
\hline & $\begin{array}{c}\text { Discharged on Iron } \\
N=106\end{array}$ & $\begin{array}{c}\text { Not Discharged on Iron } \\
\mathrm{N}=122\end{array}$ & UnivariateP value & $\begin{array}{l}\text { Multivariate } \\
\text { OR, }(95 \% \text { CI })\end{array}$ \\
\hline Mean Age ( \pm SD) & $63.4(13.6)$ & $61.9(14.2)$ & 0.42 & \\
\hline $\begin{array}{c}\text { Hemoglobin, g/dl }( \pm \text { SD }) \\
\text { Admission } \\
\text { Nadir } \\
\text { Discharge } \\
\end{array}$ & $\begin{array}{l}7.6(2.3) \\
6.4(1.4) \\
8.7(0.8) \\
\end{array}$ & $\begin{array}{l}9.1(2.7) \\
6.8(1.4) \\
8.6(0.8) \\
\end{array}$ & $\begin{array}{c}<\mathbf{0 . 0 0 1} \\
\mathbf{0 . 0 2} \\
0.73 \\
\end{array}$ & $\begin{array}{c}1.9,0.99-3.7 \\
1.1,0.8-1.5\end{array}$ \\
\hline Ferritin, ng/ml $( \pm$ SD $)$ & $10.9(8.5)$ & $15.9(8.3)$ & 0.008 & \\
\hline $\begin{array}{c}\text { Transferrin Saturation } \\
( \pm \text { SD })\end{array}$ & $5.5(2.6)$ & $7.4(3.3)$ & 0.002 & \\
\hline Blood Transfusion (\%) & 85.8 & 71.3 & .008 & $2.72,1.1-6.9$ \\
\hline Alcohol Abuse (\%) & 27.4 & 19.7 & 0.17 & \\
\hline $\begin{array}{c}\text { Anticoagulation (\%) } \\
\text { Warfarin } \\
\text { Direct Oral } \\
\text { Anticoagulant } \\
\text { Clopidogrel/Ticagrelor } \\
\text { Aspirin/NSAID } \\
\end{array}$ & $\begin{array}{l}10.4 \\
14.2 \\
19.8 \\
50.0 \\
25.5\end{array}$ & $\begin{array}{c}7.4 \\
9.0 \\
15.6 \\
45.1 \\
22.1\end{array}$ & $\begin{array}{l}0.42 \\
0.22 \\
0.40 \\
0.46 \\
0.55\end{array}$ & \\
\hline $\begin{array}{c}\text { Iron During Admission } \\
\text { Oral/IV/Combined }\end{array}$ & 70.8 & 15.6 & $<0.001$ & $13.6,7.0-26.6$ \\
\hline
\end{tabular}

SD - Standard Deviation

NSAID - non-steroidal anti-inflammatory drug 
Frank Friedenberg et al.

Table 2: Comparison of outcomes between patients discharged on and off iron.

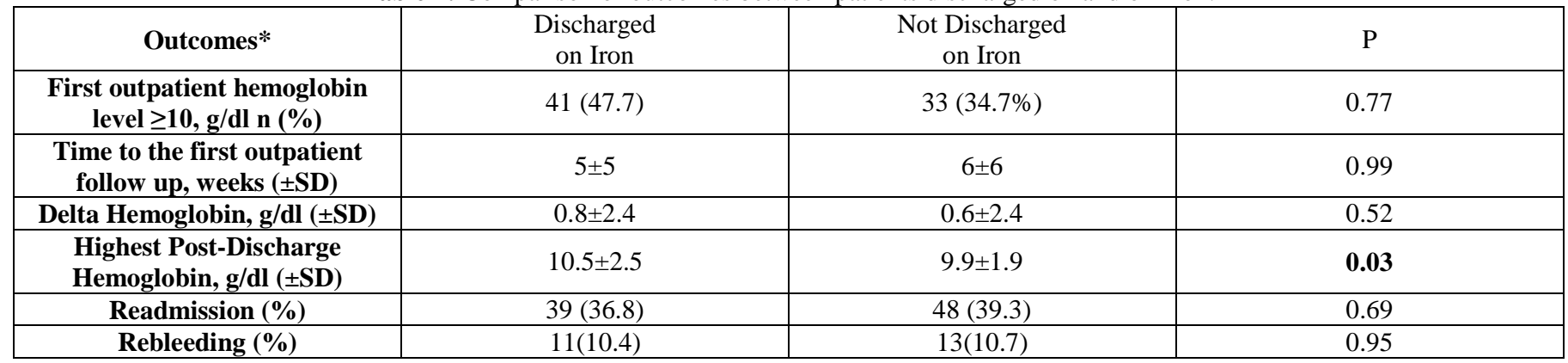

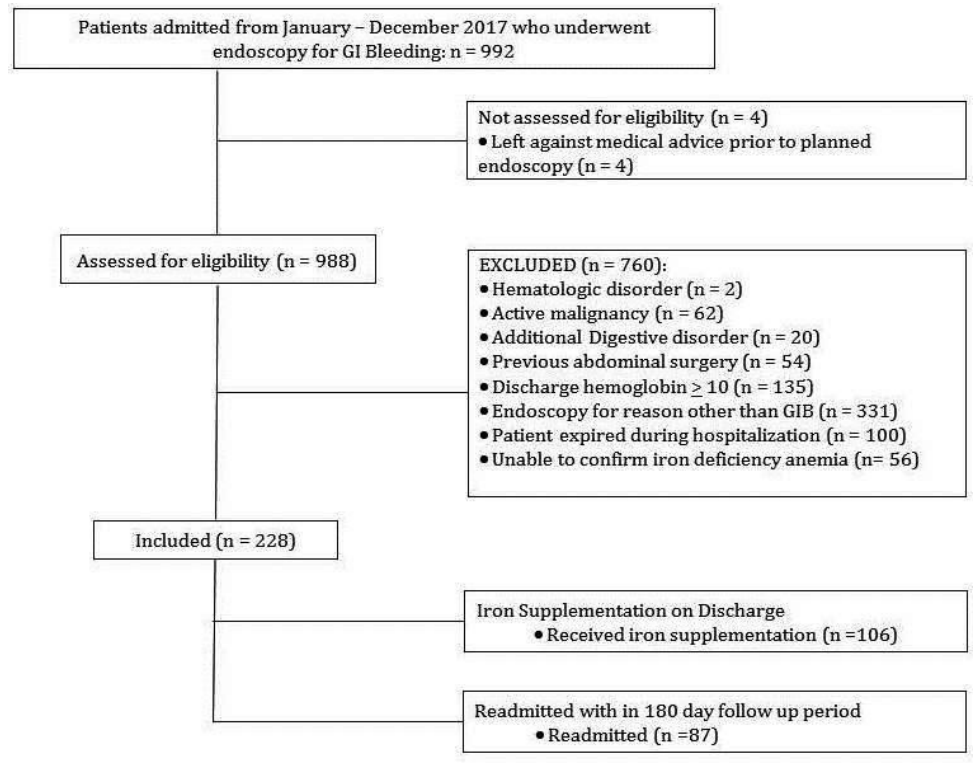

Figure 1: Study Flow Diagram.

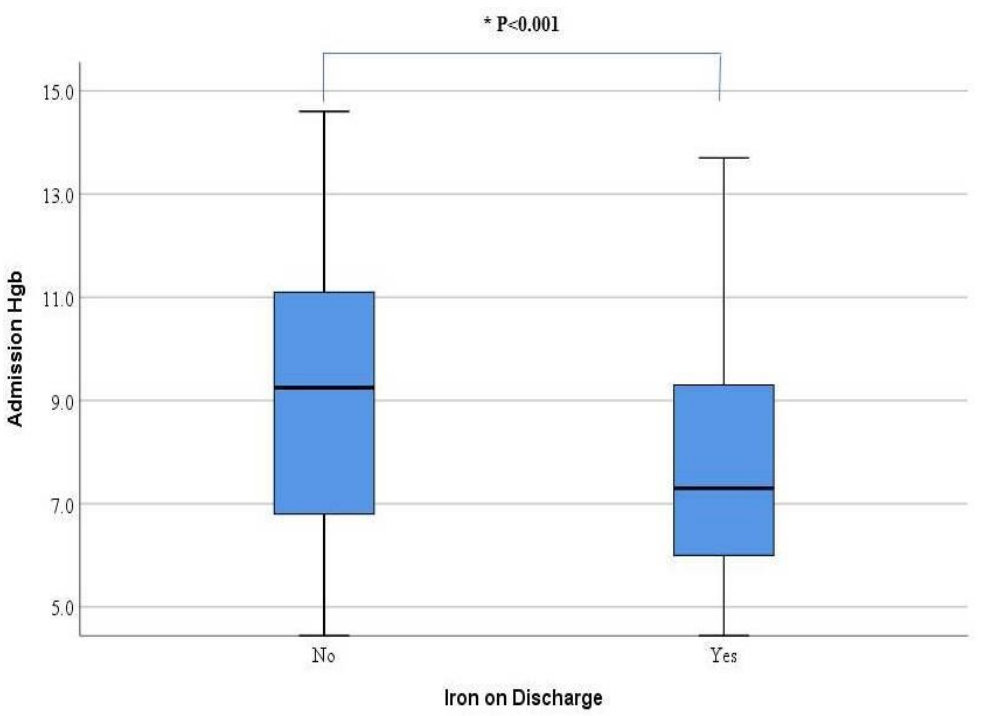

Figure 2: Boxplot and whiskers showing relationship between receiving iron on discharge and admission hemoglobin. Median admission hgb was significantly lower $(\mathrm{p}<0.001)$ for those receiving iron.

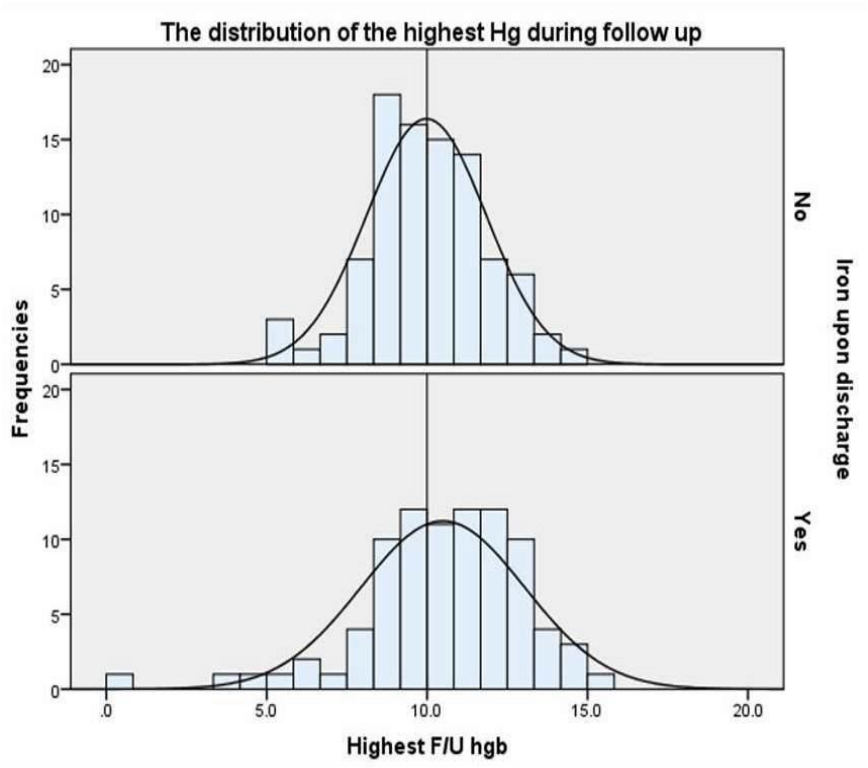

Figure 3: Distribution of highest hemoglobin values after discharge stratified by whether patient received iron on discharge.

\section{Discussion}

At our institution, physicians failed to provide iron supplementation on discharge to over $50 \%$ of eligible patients after an episode of GI bleeding with the presence of either iron deficiency and/or $a \geq 2 \mathrm{~g} / \mathrm{dL}$ drop in hemoglobin with a discharge hgb of $<10.0$ $\mathrm{g} / \mathrm{dL}$. Having received a blood transfusion or iron supplementation during the hospital stay independent of the admission, nadir or discharge hemoglobin were strongly associated with receiving a prescription for iron on discharge. We believe that the reason for the association of iron supplementation during hospitalization with this outcome was due to medication reconciliation performed automatically by the EMR (EPIC Hyperspace®, EPIC Systems Corporation, Verona, WI) at the time of discharge. 


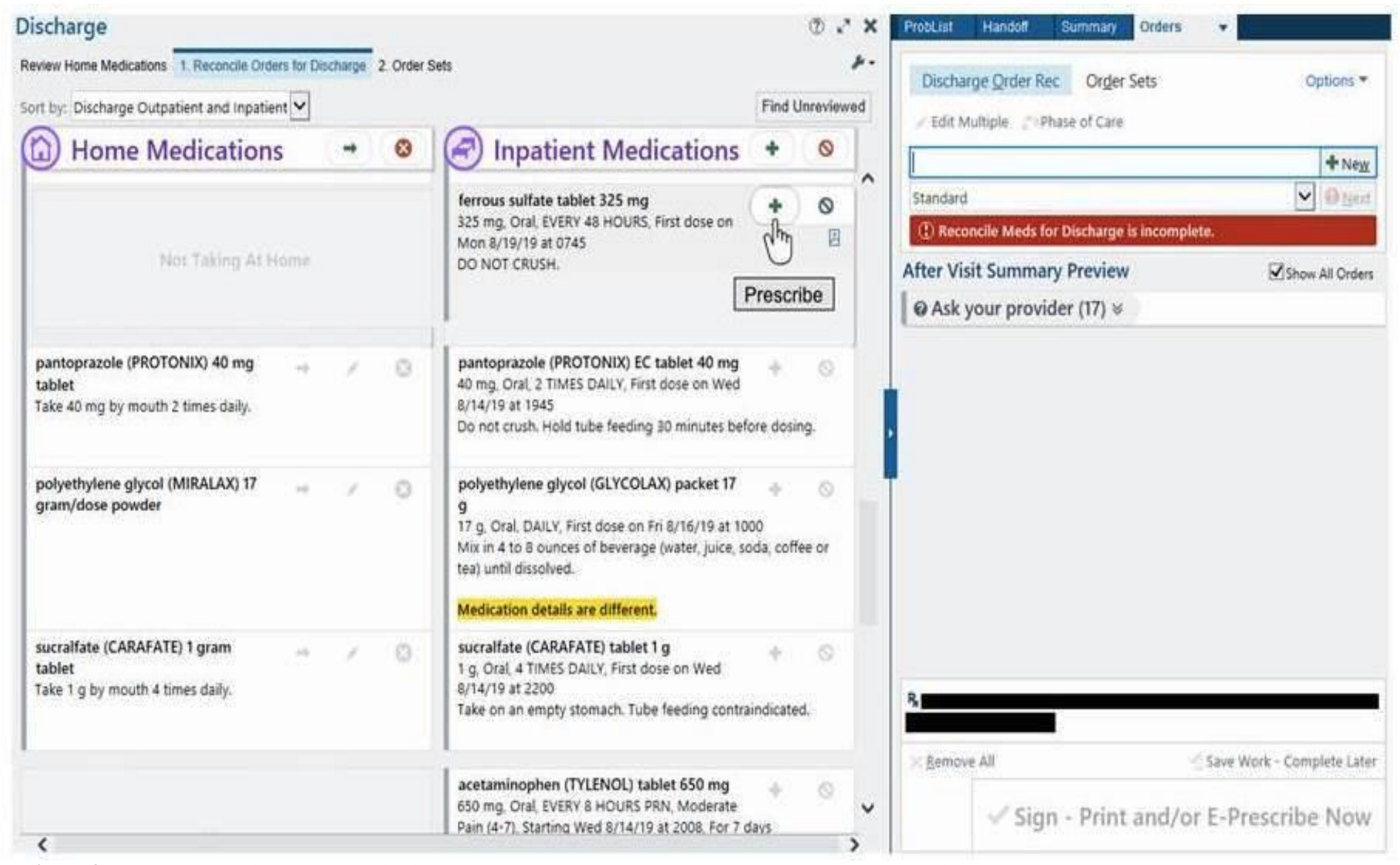

Figure 4: Screen capture of discharge medication reconciliation (EPIC Hyperspace $®$, EPIC Systems Corporation, Verona, WI). Prompts query whether to continue home and inpatient medications upon discharge. On the discharge pathway there are two columns; one lists home medications prior to admission, the other is for medications currently receiving while hospitalized. At discharge the physician must choose to continue, modify or stop home and inpatient medications. In this figure the patient was previously not on ferrous sulfate supplementation but was started on this medication during his hospitalization and the physician is prompted to either prescribe this medication or discontinue it.

Iron is required for heme synthesis of hemoglobin, which binds oxygen molecules for delivery to body tissues. Cardiac muscles utilize iron for oxygen diffusion into mitochondria [8]. Life threatening conditions may ensue due to a lack of iron such as worsening pulmonary hypertension and heart failure as well as impairment of immune function $[9,10]$. Ruiter et al, found that iron deficient patients with idiopathic pulmonary hypertension had significantly reduced 6 minute walking distance compared with iron sufficient patients, demonstrating that iron is crucial for preserving exercise performance [10]. Similarly, Krasuski et al, found that survival in those with pulmonary hypertension paralleled hemoglobin levels [11]. For patients with heart failure, those with iron deficiency treated with intravenous iron supplementation showed not only improvement in functional capacity and quality of life but also a reduction in symptoms and hospital readmission [12]. Lastly, IDA can lead to decreased cell-mediated immunity, especially to intracellular pathogens, which increases a patient's susceptibility to infections.
For example, macrophages need iron as a cofactor to perform important antimicrobial functions, which include oxidative bursts and the production of nitrogen radicals to eradicate intracellular bacteria [13].

Our results on the failure to provide iron supplementation on discharge to $>50 \%$ of eligible patients are similar to other studies examining this issue. In a retrospective review El-Halabi et al, found that IDA was not only under-treated in GI bleeding but was also under-diagnosed. In their study, among patients admitted with GI bleeding, $47.4 \%$ had confirmed IDA and only $64 \%$ of those confirmed were discharged with iron supplementation [14]. Likewise, Bager et al, found that only $16 \%$ of patients with acute upper GI bleeding were discharged with iron supplementation and noted the lack of standardized guidelines for treatment of post-discharge anemia in this setting [15]. 
Although we found no statistically significant reduction for readmission rates, our retrospective study may have been underpowered for this secondary endpoint. We did find that patients receiving iron supplementation on discharge had a trend toward higher hemoglobin values on post-discharge testing. However this finding did not reach statistical significance. Larger studies will be needed to determine the value of iron supplementation on preventing morbidity and readmission after discharge in this setting.

In theory, the implications for failing to provide patients with appropriate iron supplementation are significant. Replenishing iron stores is of utmost importance in order to reduce anemia progression and the risk of end organ damage. Patients with upper GI bleeding experience a recurrence within 4 weeks at a rate of $26 \%$ and $19 \%$ within one year for lower GI bleeding $[16,17]$. These individuals are at particular risk of end organ damage due to diminished iron reserve. Bosch et al performed a prospective 8-year cohort study that attempted to identify independent factors which predict hospitalization for patients with IDA. These risk factors included age $>65$ years, living alone, a post-transfusion hemoglobin level of $<9 \mathrm{~g} / \mathrm{dL}$, higher age-adjusted overall comorbidity, heart failure, and poor physical health-related quality of life [18].
These risk factors are imperative to identify to arrange for immediate iron supplementation.

Iron has traditionally been supplemented as oral iron. Oral iron regimens have varied without standard dosing recommendations. Recent data suggests that every other day dosing increases absorption [19]. However, oral iron supplementation may not be well tolerated, most commonly due to gastrointestinal irritation. While there are many formulations and strategies to supplement iron stores, this remains an area necessitating quality improvement. Intravenous (IV) iron supplementation is an alternative solution for treating IDA. Indications for IV iron include intolerance to oral therapy, poor intestinal absorption, and when an expedited increase in hemoglobin is needed such as in severe anemia. IV iron is also useful in patients with chronic kidney disease as these formulations bypass physiologic regulation of absorption from the gastrointestinal tract and effectively replenish diminished iron stores [20]. Excluding the conditions mentioned, oral supplementation remains the first line and mainstay of therapy for IDA [21]. Table 3 illustrates the various IV iron formulations and dosing guidelines [22-33].

Table 3: Current FDA approved Intravenous Iron Preparations ${ }^{22-33}$

\begin{tabular}{|c|c|c|c|c|c|}
\hline Trade Name & Iron Dextran & $\begin{array}{l}\text { Sodium Ferric } \\
\text { Gluconate }\end{array}$ & Iron Sucrose & Ferumoxytol & $\begin{array}{c}\text { Ferric } \\
\text { Carboxymaltose) }\end{array}$ \\
\hline Black box warning & Yes & No & No & Yes & No \\
\hline Test dose & $\begin{array}{l}\text { Yes }-25 \mathrm{mg}(0.5 \mathrm{~mL}) \\
\text { prior to the first dose }\end{array}$ & $\begin{array}{l}\text { Not required, } \\
\text { recommended if the } \\
\text { patient has a history of } \\
\text { multiple drug allergies }\end{array}$ & $\begin{array}{l}\text { Not required, } \\
\text { recommended if the } \\
\text { patient has a history of } \\
\text { multiple drug allergies }\end{array}$ & No & No \\
\hline $\begin{array}{l}\text { FDA Approved } \\
\text { Indication(s) }\end{array}$ & $\begin{array}{c}\text { Iron deficiency anemia } \\
\text { where oral iron } \\
\text { administration is } \\
\text { unsatisfactory or } \\
\text { impossible }\end{array}$ & $\begin{array}{c}\text { Iron deficiency anemia } \\
\text { in adult and pediatric } \\
\text { CKD patients receiving } \\
\text { hemodialysis }\end{array}$ & $\begin{array}{c}\text { Iron deficiency anemia } \\
\text { in pediatric patients with } \\
\text { non-dialysis dependent, } \\
\text { hemodialysis dependent, } \\
\text { and peritoneal dialysis } \\
\text { CKD }\end{array}$ & $\begin{array}{l}\text { Iron deficiency anemia } \\
\text { in adult patients with } \\
\text { CKD }\end{array}$ & $\begin{array}{l}\text { Iron deficiency anemia } \\
\text { in adult patients who } \\
\text { have intolerance to oral } \\
\text { iron or have had } \\
\text { unsatisfactory response } \\
\text { to oral iron or adult } \\
\text { patients with non- } \\
\text { dialysis dependent CKD }\end{array}$ \\
\hline $\begin{array}{l}\text { Concentration of } \\
\text { elemental iron }\end{array}$ & $50 \mathrm{mg} / \mathrm{mL}$ & $12.5 \mathrm{mg} / \mathrm{mL}$ & $20 \mathrm{mg} / \mathrm{mL}$ & $30 \mathrm{mg} / \mathrm{mL}$ & $50 \mathrm{mg} / \mathrm{mL}$ \\
\hline Dosing & $\begin{array}{l}\text { Dependent on patient's } \\
\text { total iron requirement. } \\
\text { For other preparations: } \\
\text { Multiple doses of } 100 \\
\text { mg or single dose of } \\
1000 \text { mg given over one } \\
\text { hour }\end{array}$ & $\begin{array}{c}\text { Multiple doses of } 125 \text { to } \\
187.5 \mathrm{mg}\end{array}$ & $\begin{array}{l}\text { Multiple doses of } 200 \text { to } \\
300 \mathrm{mg}\end{array}$ & $\begin{array}{c}\text { Two doses of } 510 \mathrm{mg} \\
\text { given three to eight days } \\
\text { apart or a single dose of } \\
1020 \mathrm{mg}\end{array}$ & $\begin{array}{l}\text { Weight } \geq 50 \mathrm{~kg} \text { : two } \\
\text { doses of } 750 \mathrm{mg} \text {, given } \\
\text { seven or more days apart } \\
\text { Weight }<50 \mathrm{~kg} \text { : two } \\
\text { doses of } 15 \mathrm{mg} / \mathrm{kg} \text { given } \\
\text { seven or more days apart }\end{array}$ \\
\hline
\end{tabular}


As this was a retrospective study, there are several weaknesses that need to be considered. For example, not all patients had a ferritin or iron panel assessed either when they were initially admitted or within the previous year. In those cases, the third criterion of IDA we developed a priori was utilized; > $2 \mathrm{~g} / \mathrm{dl}$ hemoglobin drop from the patient's known baseline value. A > $2 \mathrm{~g} / \mathrm{dl}$ hemoglobin drop as a result of GI bleeding reflects a significant loss of blood volume and therefore iron.

Furthermore, we established that a hgb value in this setting of $<10 \mathrm{~g} / \mathrm{dL}$ was an indication for supplemental iron on discharge. As this was retrospective, we could not investigate the clinical decision used to determine whether a patient was discharged with iron (i.e. unmeasured confounders). For example, a patient may have expressed a previous intolerance to this therapy. Other patients may not have received iron due to complex anemia such as that seen with chronic kidney disease or thalassemia where IDA was not recognized. Making the diagnosis of iron deficiency with iron studies and perhaps the review of the peripheral blood smear might have influenced the decision to initiate iron therapy at the time of hospital discharge.

Another weakness of this study is the inability to accurately identify patients taking iron prior to admission. Although available in the EMR, many patients are erroneously listed as taking iron therapy and we chose to not look at this variable. As this was an observational study, we were unable to standardize whether patients received a blood transfusion or iron supplementation during hospitalization. At our institution most physicians use a hemoglobin $<7 \mathrm{~g} / \mathrm{dL}$ as the threshold for red cell transfusion but there is significant variation. Although administration of IV iron supplementation has been shown to improve symptoms, functional capacity, as well as quality of life, there are no specific guidelines for inpatient administration at our institution [34].

At our institution iron supplementation started during hospitalization is the most important factor determining whether a patient admitted for GI bleeding is discharged with iron. We ascribe this factor to the medicine reconciliation process in the EMR at the time of discharge. Essentially this serves as a prompt to continue the therapy as an outpatient (Figure 4). If iron is not started, this prompt is non-existent. One possible solution is to implement a reminder system within a hospital's EMR for those discharged with a diagnosis of GI bleed meeting predetermined thresholds for blood loss and discharge hgb. Logan et al utilized EMR-generated prompts in a primary care clinic to systematically address IDA and found that with the prompt, prescribing of oral iron supplementation increased by $10 \%$ which was statistically sig- -nificant [35].

In summary, our study illustrates that for the majority of patients hospitalized for significant GI bleeding, physicians do not appropriately prescribe iron supplementation at discharge. We were not able to show that this oversight led to increased outpatient morbidity or higher readmission rates although our study was likely underpowered to identify these findings. We found that those patients who received a blood transfusion or iron supplementation in the hospital were significantly more likely to receive postdischarge iron supplementation. We ascribe the finding of the latter variable to the medicine reconciliation process of the EMR. We suggest that hospitals develop standardized pathways or prompts in the EMR to remind physicians about this critically important issue.

\section{Acknowledgments}

There were no contributors outside the listed authors.

\section{Statement of Ethics}

This study protocol was reviewed and exempt by the Institutional Review Board (reference number 26908).

\section{Conflicts of Interest:}

The authors declare no conflict of interest.

\section{Funding Sources}

None.

\section{Author Contributions}

Marina Baskharoun, MD and Sara Goff, MD are residents in the Department of Internal Medicine at Temple University Hospital and chart reviewed, collected data as well as prepared and edited the manuscript. Dr. Michael Bromberg, MD PhD is Chief of Hematology and provided expert opinion from a hematologic perspective and verified the manuscripts conclusions and recommendations. Yiting Li, MD and Lan $\mathrm{Xu}$ provided statistical analysis. Frank Friedenberg, MD MS is Chief of Gastroenterology, and provided statistical analysis as well as prepared and edited the manuscript.

\section{References:}

1. Kassebaum NJ, Jasrasaria R, Naghavi M, et al. A systematic analysis of global anemia burden from 1990 to 2010. Blood. 2014;123:615-624. 
2. Le $\mathrm{CH}$. The prevalence of anemia and moderate-severe anemia in the US population (NHANES 2003-2012). PLoS One. 2016;11:e0166635.

3. Camaschella C. Iron-deficiency anemia. N Engl J Med. 2015;372:1832-1843.

4. Auerbach M, Adamson JW. How we diagnose and treat iron deficiency anemia. Am J Hematol. 2016;91:31-38.

5. Cook JD, Skikne BS. Iron deficiency: definition and diagnosis. J Intern Med. 2020;287:153-170.

6. Carson JL, Guyatt G, Heddle NM, et al. Clinical practice guidelines from the AABB: red blood cell transfusion thresholds and storage. JAMA. 2016;316:2025-2035.

7. Tomizawa M, Shinozaki F, Hasegawa R, et al. Low hemoglobin levels are associated with upper gastrointestinal bleeding. Biomed Rep. 2016;5:349-352.

8. Haas JD, Brownlie IV T. Iron deficiency and reduced work capacity: a critical review of the research to determine a causal relationship. J Nutr. 2001;131:676S-688S.

9. Van Veldhuisen DJ, Anker SD, Ponikowski P, Macdougall IC. Anemia and iron deficiency in heart failure: mechanisms and therapeutic approaches. Nat Rev Cardiol. 2011;8:485-493.

10. Ruiter G, Lankhorst S, Boonstra A, et al. Iron deficiency is common in idiopathic pulmonary arterial hypertension. Eur Respir J. 2011;371386-1391.

11. Krasuski RA, Hart SA, Smith B, et al. Association of anemia and long-term survival in patients with pulmonary hypertension. Int J Cardiol. 2011;150:291-295.

12. Ponikowski P, Van Veldhuisen DJ, Comin-Colet J, et al. Beneficial effects of long-term intravenous iron therapy with ferric carboxymaltose in patients with symptomatic heart failure and iron deficiency. Eur Heart J. 2015;36:657-668.

13. Collins HL. The role of iron in infections with intracellular bacteria. Immunol Lett. 2003;85:193-195.

14. El-Halabi MM, Green MS, Jones C, Salyers Jr WJ. Underdiagnosing and under-treating iron deficiency in hospitalized patients with gastrointestinal bleeding. World J Gastrointest Pharmacol Ther. 2016; 7:139-144.

15. Bager P, Dahlerup JF. Lack of follow-up of anemia after discharge from an upper gastrointestinal bleeding centre. Dan Med J. 2013;60:A4583.

16. Corley DA, Stefan AM, Wolf M, et al. Early indicators of prognosis in upper gastrointestinal hemorrhage. Gastroenterology Res. 2012;5:219-226.

17. Aoki T, Nagata N, Niikura R, Shimbo T, et al. Recurrence and mortality among patients hospitalized for acute lower gastrointestinal bleeding. Clin Gastroenterol Hepatol. 2015;13:488-494.
18. Bosch X, Monclús E, Inciarte A, et al. Factors associated with hospitalization among emergency department patients referred for quick investigation of iron-deficiency anemia. J Emerg Med. 2016 Mar;50(3):394-402.

19. Stoffel NU, Cervamondi CI, Brittenham G, et al. Iron absorption from oral iron supplements given on consecutive versus alternate days and as single morning doses versus twice-daily split dosing in iron-depleted women: two open-label, randomized controlled trials. Lancet Haematol. 2017;4:e524e533.

20. Roger SD. Practical considerations for iron therapy in the management of anaemia in patients with chronic kidney disease. Clin Kidney J. 2017; 10: i9-i15.

21. Camaschella C. Iron deficiency: new insights into diagnosis and treatment. Hematology. 2015;2015(1):8-13.

22. Auerbach M. Ferumoxytol as a new, safer, easierto-administer intravenous iron: yes or no? Am J Kidney Dis. 2008 Nov;52(5):826-9.

23. Weiss G, Goodnough LT. Anemia of chronic disease. N Engl J Med. 2005;352:1011-1023.

24. Shander A, Spence RK, Auerbach M. Can intravenous iron therapy meet the unmet needs created by the new restrictions on erythropoietic stimulating agents? Transfusion. 2010;50:719-732.

25. Auerbach M, Goodnough LT, Picard D, Maniatis A. The role of intravenous iron in anemia management and transfusion avoidance. Transfusion. 2008;48:988-1000.

26. Chertow GM, Mason PD, Vaage-Nilsen O, Ahlmén J. Update on adverse drug events associated with parenteral iron. Nephrol Dial Transplant. 2006;21:378-382.

27. Ganzoni AM. Intravenous iron-dextran: therapeutic and experimental possibilities. Schweiz Med Wochenschr. 1970;100:301-303.

28. Dexferrum [package insert]. Shirley, NY, USA: American Regent; 2008.

29. INFeD [package insert]. Morristown, NJ, USA: Watson Pharma; 2009.

30. Ferrlecit [package insert]. Bridgewater, NJ, USA: Sanofi-Aventis US; 2011.

31. Venofer [package insert]. Shirley, NY, USA: American regent; 2012.

32. Feraheme [package insert]. Lexington, Mass, USA: AMAG Pharmaceuticals; 2015.

33. Injectafer [package insert]. Shirley, NY, USA: American Regent; 2013. 
34. Anker SD, Comin Colet J, Filippatos G, Willenheimer R, et al. Ferric carboxymaltose in patients with heart failue and iron deficiency. N Engl J Med.2009;361:2436-2448.

35. Logan EC, Yates JM, Stewart RM, et al. Investigation and management of iron deficiency anaemia in general practice: a cluster randomised controlled trial of a simple management prompt. Postgrad Med J. 2002;78:533-537. 